\title{
Reseña bibliográfica: Stevens, K. (2019). Between Greece and Babylonia: Hellenistic Intellectual History in Cross- Cultural Perspective, Cambridge: Cambridge University Press, 444 pp.
}

Palabras claves: Helenismo - Historia intelectual - Mesopotamia - Grecia

Keywords: Hellenism - Intellectual history - Mesopotamia - Greece

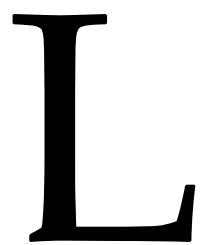

a cuestión de las relaciones entre griegos y nativos durante el período Helenístico ha llamado la atención de los estudiosos desde hace más de un siglo. En las últimas décadas se ha asistido a una renovación de este interés desde perspectivas post-constructivistas e interdisciplinarias, que han abierto nuevas vetas de investigación y han hecho progresar nuestro entendimiento de aquellas relaciones. Mesopotamia ha ocupado un lugar especial en estas consideraciones, en tanto para el momento en que los griegos establecieron una presencia permanente en la región, esta ya contaba con una larga tradición política e intelectual. Resulta sumamente interesante analizar la interacción de esta tradición local con aquella griega recién llegada, siendo una de las principales dificultades para el investigador el contar con la capacidad de acceder al registro de ambas culturas a la vez y poder establecer comparaciones.

En este sentido, Between Greece and Babylonia tiene dos grandes cualidades. Primero, es una magnífica muestra de la habilidad de Kathryn Stevens para desplazarse entre dos campos historiográficos con objetos, métodos y tradiciones tan dispares que muchas veces aparecen como irreconciliables: la asiriología y los estudios clásicos. Segundo, esta capacidad de la autora encaja perfectamente con las exigencias del objeto de estudio abordado, es decir, la cultura intelectual durante el período helenístico. En efecto, hay que reconocer que la naturalidad con la que Stevens pasa de estudiar diarios astronómicos babilónicos a analizar inscripciones religiosas de Rodas es sumamente meritoria. A su vez, es muestra de la labor requerida para abordar un objeto de dimensiones tan amplias. La obra tiene innegablemente éxito en este sentido.

Los propósitos de este libro son variados. El primero y más evidente es la formulación de un nuevo paradigma para la historia intelectual helenística. No es novedosa la definición que se da de este ámbito, que sería simplemente la historia de la cultura 
intelectual y de la actividad cultural. Lo específico de su planteamiento queda en claro cuando se considera su otro objetivo, íntimamente ligado al anterior. Así, la obra responde a un esfuerzo por abandonar el helenocentrismo que ha abundado en la materia durante mucho tiempo. En efecto, se ha solido privilegiar el estudio de elementos culturales definidos a priori como griegos presentes en ámbitos no-griegos, y esto es también cierto para el caso del estudio de la actividad de intelectuales griegos y babilónicos. Así, Stevens no duda en hacer amplio uso de aquellas obras que se enfocaron en el camino opuesto, respondiendo no ya a la pregunta de "¿qué hay de griego en Mesopotamia?”, sino de “¿qué hay de mesopotámico en Grecia?”. Esta cuestión, que no resulta una novedad, es simplemente usada como una base para ir en contra de la tradición helenocéntrica de principios y mediados del siglo pasado. En cambio, la obra también se presenta como superadora de aquella tradición orientalizante que predominó durante las últimas décadas del siglo XX, y que propugnaba por resaltar la invariabilidad de las sociedades no-griegas de Asia y África. ${ }^{1}$

En tercer lugar, teniendo en cuenta el contexto de un sistema de estados monárquicos inestables que a menudo ha atraído la mayor atención de los historiadores, hay una búsqueda de repensar la dialéctica global/local en el mundo helenístico, revalorizando este último término y mostrando la necesidad de comprender primero lo inmediato (y con esto nos referimos al nivel de la pequeña comunidad política) para poder pasar luego al orden imperial.

A la luz de todos estos planteamientos podemos comprender la principal propuesta de la autora: ofrecer, desde la historia intelectual, un intento de redefinir el significado de "lo helenístico". ¿Qué era exactamente el mundo helenístico? Mejor dicho, ¿por qué nos arrogamos la capacidad de hablar de "un" mundo helenístico, como un todo con características definidas? Evidentemente el interrogante supera el ámbito de estudio propio de la obra. En realidad, el tema abordado parece servir, al final, como un terreno de pruebas del nuevo concepto elaborado por la autora. Este consiste, antes que nada, en un rechazo de las perspectivas que realzan el papel de la cultura griega. Stevens es clara al decir que debe ser descartada la idea de Rostovtzeff (1941) de que la unidad cultural del mundo helenístico se reduce a la "grecidad" que unía levemente a las elites políticas urbanas. Podría parecer que esta ha sido abandonada hace tiempo, sobre todo con la renovación historiográfica que sobrevino tras la superación (nunca absoluta) de perspectivas que más férreamente defendían el aislacionismo de las culturas. Para la autora, es evidente que las conceptualizaciones más poderosas sobre el mundo helenístico son las que combinan un plano político (la dominación de grandes monarquías grecomacedónicas) y lo cultural (un reconocimiento de elementos griegos compartidos). Así, Erskine afirma que es "el legado de Alejandro, cultural y político, lo que da unidad y coherencia al período helenístico" (Erskine, 2003, 3). Pero esto no

\footnotetext{
${ }^{1}$ Para una visión general de esta postura, ver Préaux (1984). Para el caso específico de Mesopotamia en el marco del Imperio Seléucida, Kuhrt y Sherwin-White (1987) y Kuhrt y Sherwin-White (1993).
} 
debería llevar a un sobredimensionamiento de "lo griego" por sobre los elementos culturales nativos y de ahí el esfuerzo que la autora emprende para desligar "lo helenístico" de "lo griego".

Su planteo parte de que hay fundamentalmente dos formas de identificar e interpretar la presencia de rasgos compartidos por diferentes grupos sociales y culturales en un contexto dado, que aquí no significa otra cosa que encontrar la base para hablar de unidad del mundo helenístico. A la primera forma ella la denomina "herodotea” y es el estudio de rasgos compartidos productos de intercambios o préstamos culturales (crosscultural borrowings). Se trata, pues, de realizar una genealogía, un rastreo de cierta práctica o idea a lo largo de la historia, lo que implica un enfoque diacrónico y específico. El segundo método, y por el que Stevens apuesta, responde a un análisis estructural y sincrónico. No se trata tanto de ver rasgos concretos y puntuales (como podrían serlo ciertas prácticas adivinatorias astrológicas), sino de buscar coincidencias a través de la comparación. Los rasgos similares no se darían debido a una trasferencia gracias a contacto directo, sino que responderían a condiciones similares presentes en las entidades globales del contexto (esto es, estructuras).

El libro se podría dividir en dos, de acuerdo con el uso de uno u otro enfoque. La primera parte (capítulos 2 a 5) responde al método herodoteo, y resalta el gran manejo de la bibliografía y se obtiene al final un minucioso estado de la cuestión de varias vetas de la investigación. Curiosamente, la impresión que tiene el lector es que al terminar cada capítulo se aleja más de la posibilidad de encontrar verdaderamente algo específico de la vida intelectual del mundo helenístico y, por consiguiente, de ese mundo mismo. El punto fuerte de la obra es, por tanto, la segunda parte (capítulos 6 y 7), de enfoque comparativista. Es aquí donde la autora arriesga su hipótesis principal, a saber: lo específico del ámbito intelectual helenístico es apreciado en las novedades estructurales, las cuales, a su vez, responden a transformaciones políticas amplias. Es el hecho de que una gran parte de la oikouméne se encuentre bajo el dominio de grandes monarcas macedónicos lo que estimula acciones y actitudes similares a lo largo y ancho de este gran mundo, que en muchos sentidos se ha vuelto más grande y mucho más conectado.

Al final, el gran cambio cultural y político que pregonaba Erskine sí aconteció en el mundo helenístico, y de hecho lo definió. Pero no vino, como señaló Rostovtzeff, de la extensión de cierta cultura griega elitista. En realidad, plantea Stevens, ese cambio se produjo por la más evidente y simple instauración de nuevas monarquías, pero que trajo consecuencias con efectos más amplios: redefiniciones de las redes de poder y mayor circulación y disponibilidad de información en general. Los intelectuales helenísticos son el caso perfecto para apreciar la nueva sensibilidad a tales variaciones, pues, como demuestra Stevens, supieron hacer una lectura atinada de su contexto y adaptarse al mismo con éxito. Particularmente visible resulta esta interacción cuando se tiene en cuenta el nivel de lo local, preocupación principal del capítulo 7.

Al final, la propuesta de Stevens resulta convincente y hasta cautivadora. Su erudición y capacidad de análisis no dejan de traslucirse a lo largo de toda la obra. Si 
algo se le puede reclamar, sin embargo, es la necesidad de un estudio más profundo de esta perspectiva, sobre todo en vistas de analizar su capacidad de operar en dimensiones más allá del campo intelectual, como la sociedad y la política.

\section{Referencias bibliográficas}

Erskine, A. (2003). Approaching the Hellenistic world. A companion to the Hellenistic World. En A. Erskine (Ed.), A companion to the Hellenistic world (pp. 1-15). Oxford: Blackwell Publishing Ltd.

Kuhrt, A. y Sherwin-White, S. (Eds.) (1987). Hellenism in the East: The interaction of Greek and non-Greek civilizations from Syria to Central Asia after Alexander. Los Angeles: University of California Press.

Préaux, C. (1984). El mundo helenístico: Grecia y Oriente desde la muerte de Alejandro hasta la conquista de Grecia por Roma (323-146 a. de C.). Barcelona: Editorial Labor.

Rostovtzeff, M. I. (1941). The social E economic history of the Hellenistic world. Oxford: Clarendon Press.

Sherwin-White, S. M. y Kuhrt, A. (1993). From Samarkhand to Sardis: a new approach to the Seleucid empire. Los Angeles: University of California Press.

Ezequiel Martin Parra

Universidad Nacional de Córdoba

eze.marp@gmail.com

Para citar esta reseña:

Martin Parra, Ezequiel (2021): Reseña bibliográfica, “Stevens, K. (2019). Between Greece and Babylonia: Hellenistic Intellectual History in Cross-Cultural Perspective, Cambridge: Cambridge University Press, 444 pp." Anuario de la Escuela de Historia Virtual 19, 188-191. 